Article

\title{
Development of Stochastic Fatigue Model of Reinforcement for Reliability of Concrete Structures
}

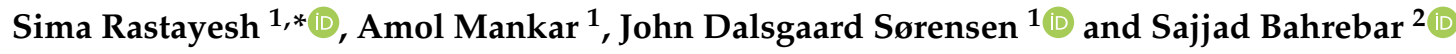 \\ 1 Department of Civil Engineering, Aalborg University, 9100 Aalborg, Denmark; ama@civil.aau.dk (A.M.); \\ jds@civil.aau.dk (J.D.S.) \\ 2 Department of Mechanical Engineering, Technical University of Denmark, 2800 Lyngby, Denmark; \\ sajbahr@mek.dtu.dk \\ * Correspondence: sir@civil.aau.dk
}

Received: 15 November 2019; Accepted: 8 January 2020; Published: 14 January 2020

\begin{abstract}
This paper presents recent contributions to the Marie Skłodowska-Curie Innovative Training Network titled INFRASTAR (Innovation and Networking for Fatigue and Reliability Analysis of Structures-Training for Assessment of Risk) in the field of reliability approaches for decision-making for wind turbines and bridges. Stochastic modeling of uncertainties for fatigue strength parameters is an important step as a basis for reliability analyses. In this paper, the Maximum Likelihood Method (MLM) is used for fitting the statistical parameters in a regression model for the fatigue strength of reinforcement bars. Furthermore, application of the Bootstrapping method is investigated. The results indicate that the latter methodology does not work well in the considered case study because of run-out tests within the test data. Moreover, the use of the Bayesian inference with the Markov Chain Monto Carlo approach is studied. These results indicate that a reduction in the statistical uncertainty can be obtained, and thus, better parameter estimates are obtained. The results are used for stochastic modelling in reliability assessment of a case study with a composite bridge. The reduction in statistical uncertainty shows high impact on the fatigue reliability in a case study on the Swiss viaduct Crêt De l'Anneau.
\end{abstract}

Keywords: Bayesian inference; bootstrap method; Maximum Likelihood Method; reinforced-concrete; uncertainty; fatigue-resistance

\section{Introduction}

This paper presents statistical analyses performed on fatigue data obtained from [1], where laboratory fatigue tests were performed on reinforcement bars (rebars).

General methods and techniques utilized for risk and reliability assessment of civil engineering structures are presented [2-18].

Statistical analyses of the data are an essential step for the stochastic modeling of the material fatigue uncertainties, which can next be used as a basis for a probabilistic modeling and reliability analysis [19] of structures with reinforced concrete components, such as wind turbines and bridges [20,21]. Usually, foundations for onshore wind turbines are constructed by the use of reinforced concrete, which is also used in many bridges. Therefore, the development of stochastic models for the fatigue limit state and estimation of the resulting reliability can be considered as a contribution to reliability assessment of these types of structures, with respect to fatigue failure and also as the basis for the development of optimal strategies for the maintenance of wind turbines and bridges. [22].

Several methodologies can be used to estimate the statistical parameters. For instance: Maximum Likelihood Method (MLM), moment method, least square method, and Bayesian statistics. In the literature, there are some recommendations indicating which of these methods could be more suitable. 
At the same time, there is no unique answer to this question, especially for a fatigue case study on rebars. On the reliability assessment, choosing a specific method has a direct influence. In the reliability assessment, there is a need to have stochastic modeling for the material-resistance as well as for the loads. In this paper, the material-resistance model is presented in detail, and at the end, using a generic stochastic model for the fatigue load reliability results of a composite bridge are presented.

The MLM is chosen in this study as it gives an estimate of the statistical uncertainties [23]. MLM is considered for fitting the statistical parameters [2] in a regression model for fatigue strength. Typically, the statistical analyses are based on a limited number of data, for which MLM can provide estimates of the uncertainties associated with each of these parameters and the correlation between the parameters [24]. This paper also presents the use of the Bootstrap method, which generates synthetic data based on the available measurements from the experiment.

Further, Bayesian statistics is considered taking subjective/prior information into account. This is done with application of Bayesian inference with a Markov Chain Monte Carlo implementation [25-27]. Bayesian updating is an appropriate tool to update the structural performance function for fatigue by applying the information from the structural health monitoring and the prior information about different fatigue parameters. The aim is to compare the results of different methodologies and to provide information in order to select an appropriate method.

To study the effect of uncertainty of fatigue resistance model on the fatigue reliability of a structure, a case study of Swiss viaduct Crêt De l'Anneau is presented. For this structure, long term strain monitoring data on critical reinforcement is available.

\section{Materials and Methods}

\subsection{Test Data}

Test data on the fatigue strength test for steel reinforcement from the lab tests were done at Aalborg University by Hansen and Heshe [1]. It is utilized for the statistical analysis to determine typical fatigue strength uncertainties (see Table 1 , where 1 indicated run-out/no failure and 0 indicates failure). The lab tests are performed with steel reinforcement bars with $16 \mathrm{~mm}$ of diameter and yields strengths of $570 \mathrm{MPa}$. The S-N curve for this data is presented in Figure 1. Run-outs are depicted in orange and failures in gray.

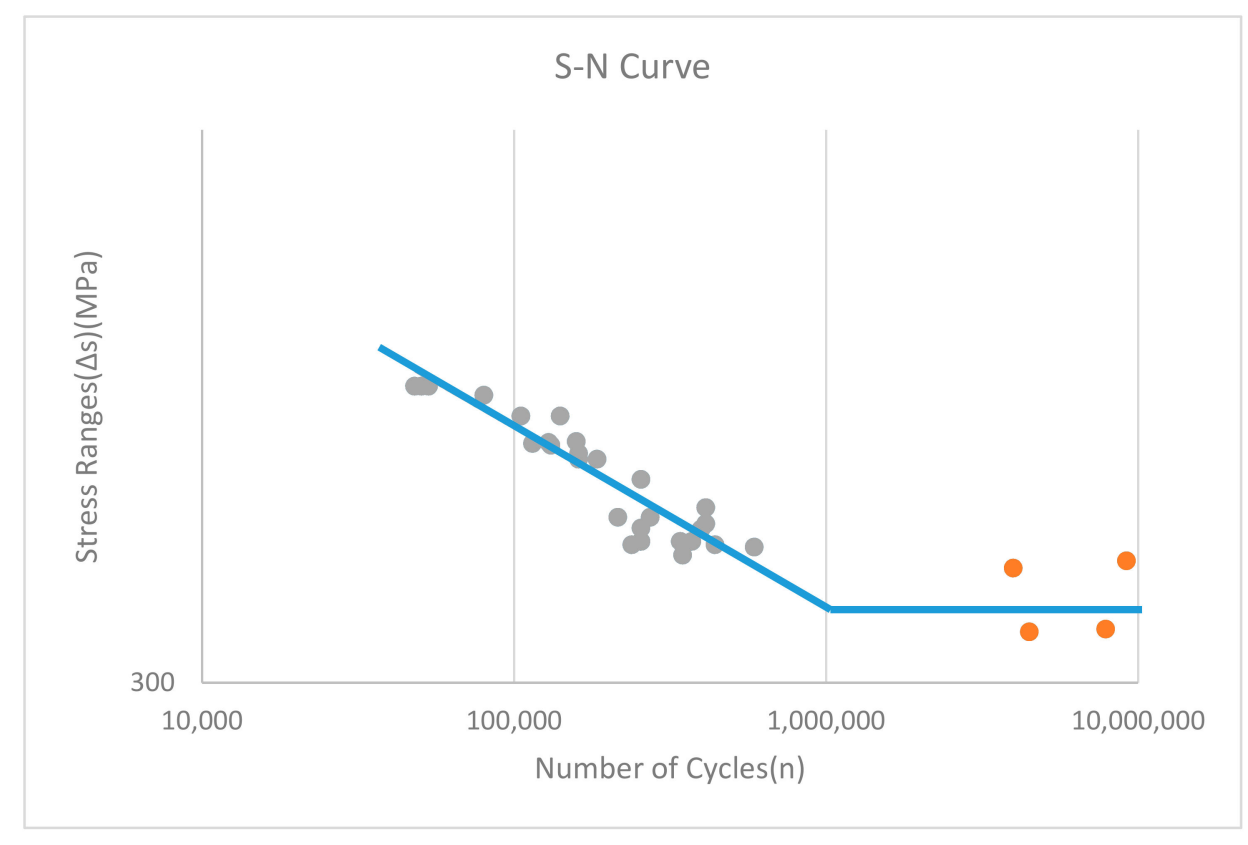

Figure 1. S-N curve for rebar data [1]. 
Table 1. Data [1].

\begin{tabular}{|c|c|c|c|}
\hline Data Number (Index) & Number of Cycles to Failure & Stress Range [MPa] & Run-Out \\
\hline 1 & $7,875,829$ & 337 & 1 \\
\hline 2 & $4,485,923$ & 335 & 1 \\
\hline 3 & $9,182,542$ & 391 & 1 \\
\hline 4 & $3,981,071$ & 385 & 1 \\
\hline 5 & 347,328 & 396 & 0 \\
\hline 6 & 589,346 & 403 & 0 \\
\hline 7 & 441,005 & 405 & 0 \\
\hline 8 & 371,852 & 408 & 0 \\
\hline 9 & 341,454 & 408 & 0 \\
\hline 10 & 238,658 & 405 & 0 \\
\hline 11 & 255,509 & 408 & 0 \\
\hline 12 & 255,509 & 420 & 0 \\
\hline 13 & 273,550 & 430 & 0 \\
\hline 14 & 215,443 & 430 & 0 \\
\hline 15 & 411,921 & 439 & 0 \\
\hline 16 & 398,107 & 419 & 0 \\
\hline 17 & 411,921 & 424 & 0 \\
\hline 18 & 255,509 & 467 & 0 \\
\hline 19 & 184,784 & 488 & 0 \\
\hline 20 & 161,215 & 488 & 0 \\
\hline 21 & 161,215 & 494 & 0 \\
\hline 22 & 131,376 & 503 & 0 \\
\hline 23 & 114,619 & 505 & 0 \\
\hline 24 & 129,154 & 506 & 0 \\
\hline 25 & 158,489 & 507 & 0 \\
\hline 26 & 140652 & 536 & 0 \\
\hline 27 & 105,250 & 536 & 0 \\
\hline 28 & 80,113 & 561 & 0 \\
\hline 29 & 53,201 & 572 & 0 \\
\hline 30 & 48,026 & 572 & 0 \\
\hline 31 & 50,547 & 572 & 0 \\
\hline
\end{tabular}

\subsection{Statistical Analysis of Fatigue Data of Steel Reinforcing Bars}

For steel reinforcement bars used in concrete $\mathrm{S}-\mathrm{N}$, curves are recommended by various international codes (such as Model code 2010, Model code 1990, DNV OS C 502, EN 1992-1) [28-31] and are generally written as:

$$
n_{i}=K \Delta s_{i}^{-m}
$$

or

$$
\log \left(n_{i}\right)=\log (K)-m \log \left(\Delta s_{i}\right),
$$

where $n_{i}$ is the number of cycles to failure with stress range $\Delta s_{i}$ in test number, i. $K$ and $m$ are fatigue parameters to be fitted by MLM here using test data [31].

To account for uncertainties in fatigue life, Equation (2) can be rewritten [22]:

$$
\log \left(n_{i}\right)=\log (K)-m \log \left(\Delta s_{i}\right)+\varepsilon,
$$

where $\varepsilon$ represents the uncertainty of the fatigue life model and is modelled by a stochastic variable with mean value equal to zero and standard deviation, $\sigma_{\varepsilon} . \varepsilon$ is often assumed to have a Normal distributed [31].

The Likelihood function to be used to estimate the optimal values of the parameters $K, m$, and $\sigma_{\varepsilon}$ from test data is written [22]:

$$
L\left(K, m, \sigma_{\varepsilon}\right)=\prod_{i=1}^{n_{F}} P\left[\log (K)-m \log \left(\Delta s_{i}\right)+\varepsilon=\log \left(n_{i}\right)\right] \times \prod_{i=n_{F}+1}^{n_{F}+n_{R}} P\left[\log (K)-m \log \left(\Delta s_{i}\right)+\varepsilon>\log \left(n_{i}\right)\right] .
$$


Here, $n_{i}$ is the number of stress cycles to failure or to run-out with stress range $\Delta s_{i}$ in test number $i$. $n_{F}$ is the number of tests where failure occurs, and $n_{R}$ is the number of tests where failure did not occur after $n_{i}$ stress cycles (run-outs). The total number of tests is $n=n_{F}+n_{R} . K, m$, and $\sigma_{\varepsilon}$ are obtained from the optimization problem $\max _{K, m, \sigma_{\varepsilon}} L\left(K, m, \sigma_{\varepsilon}\right)$, which can be solved using a non-linear optimization algorithm [31].

Run-outs contain information which from a statistical point of view has to be included in the statistical modelling in order to be consistent with all tests performed. This paper describes how run-outs can be included using the MLM. The number of cycles where the tests are stopped are often chosen in order to limit the costs and time used for the test campaign.

The terms in Equation (4) can be obtained from Equation (5) [22]:

$$
\begin{gathered}
P\left[\log (K)-\operatorname{mlog}\left(\Delta s_{i}\right)+\varepsilon=\log \left(n_{i}\right)\right]=\frac{1}{\sqrt{2 \pi} \sigma_{\varepsilon}} \exp \left(-\frac{1}{2}\left(\frac{\log (K)-m \log \left(\Delta s_{i}\right)-\log \left(n_{i}\right)}{\sigma_{\varepsilon}}\right)^{2}\right), \\
P\left[\log (K)-\operatorname{mlog}\left(\Delta s_{i}\right)+\varepsilon>\log \left(n_{i}\right)\right]=\Phi\left(\frac{\log (K)-\operatorname{mlog}\left(\Delta s_{i}\right)-\log \left(n_{i}\right)}{\sigma_{\varepsilon}}\right) .
\end{gathered}
$$

The parameters $K, m$, and $\sigma_{\varepsilon}$ are generally determined using a limited number of data. Consequently, the estimates are subject to statistical/parameter uncertainty. Since the parameters are estimated by the MLM, they become asymptotically (number of data should be $>25-30$ ). Normal distributed stochastic variables with expected values equal to the maximum-likelihood estimator and a covariance matrix equal to [32]:

$$
C_{K, m, \sigma_{\varepsilon}}=\left[-H_{K, m, \sigma_{\varepsilon}}\right]^{-1}=\left[\begin{array}{ccc}
\sigma_{K}^{2} & \rho_{K, m} \sigma_{K} \sigma_{m} & \rho_{K, \sigma_{\varepsilon}} \sigma_{K} \sigma_{\sigma_{\varepsilon}} \\
\rho_{K, m} \sigma_{K} \sigma_{m} & \sigma_{m}^{2} & \rho_{m, \sigma_{\varepsilon}} \sigma_{m} \sigma_{\sigma_{\varepsilon}} \\
\rho_{K, \sigma_{\varepsilon}} \sigma_{K} \sigma_{\sigma_{\varepsilon}} & \rho_{m, \sigma_{\varepsilon}} \sigma_{m} \sigma_{\sigma_{\varepsilon}} & \sigma_{\sigma_{\varepsilon}}^{2}
\end{array}\right] .
$$

$H_{K, m, \sigma_{\varepsilon}}$ is the Hessian matrix with second-order derivatives of the log-likelihood function. $\sigma_{K}, \sigma_{m}$, and $\sigma_{\sigma_{\varepsilon}}$ denote the standard deviations of $K, m$, and $\sigma_{\varepsilon}$, respectively, and e.g., $\rho_{K, m}$ is the correlation coefficient between $K$ and $m$.

\subsection{Bootstrap Method}

The Bootstrap method developed by Efron [33] may be used for smaller samples and is quite flexible concerning the assumptions made. The Bootstrap method applies the actual distribution of the measurement errors, which are then propagated using an appropriate Monte Carlo scheme. That is, the Bootstrap method can be used to estimate the statistical (parameter) uncertainty.

Fatigue tests take very long time as it can take millions of cycles before the failure of one specimen, and changing the frequency of load application could lead to erroneous results. The Bootstrap method can be used to generate more synthetic data, which can then be used to estimate the parameter uncertainties as an alternative to the use of MLM described above.

Residuals are estimated by subtracting the calculated number of cycles to failure from the observed number of cycles in logarithmic scale. These residuals are plotted in Figure 2a, considering the case when run-outs are not included. This histogram indicates that an assumption of residuals as white noise is satisfactory and it is uniformly distributed with a mean value equal to zero. In this case, the Bootstrap method can be used, but in applications where run-outs are part of the data, the Bootstrap method cannot be used directly, as seen in Figure $2 b$.

If we plot the residuals along with their index (data number), they are random without considering run-outs, which is a basic requirement for using the Bootstrap method, as seen in Figure 3a. Random in this context means that residuals should not follow a pattern [34]. Whereas in Figure $3 \mathrm{~b}$ with run-outs, residuals are following a pattern, so this requirement to apply the Bootstrap method is not fulfilled here. 


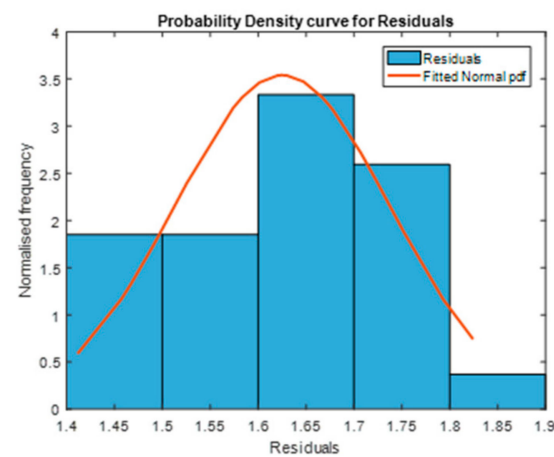

(a)

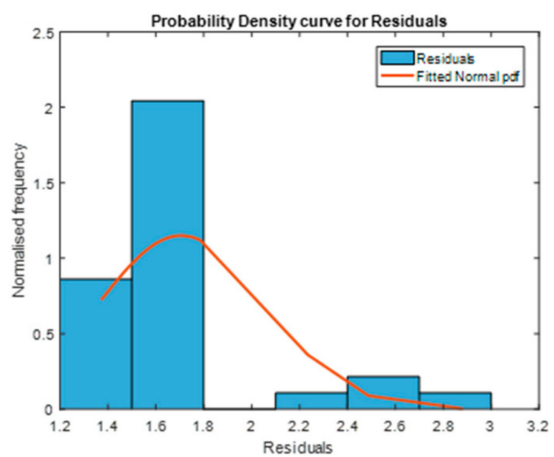

(b)

Figure 2. Histogram for Residuals: (a) without Run-outs; (b) with Run-outs.

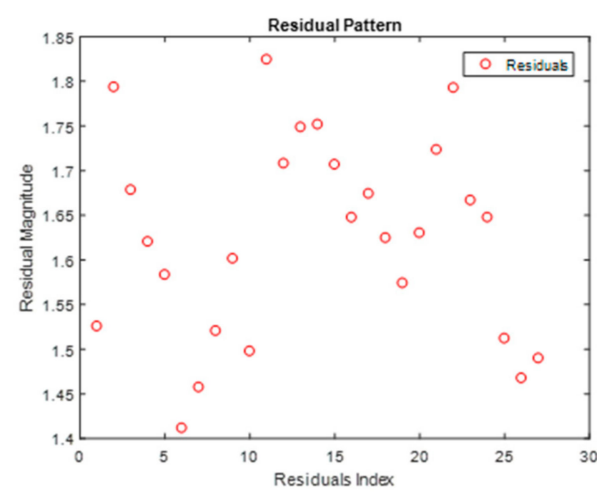

(a)

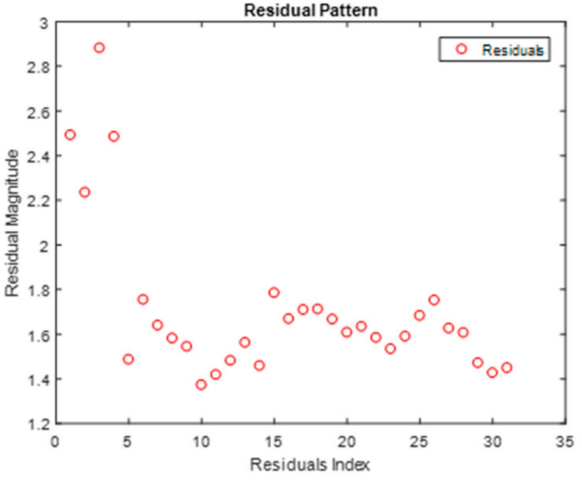

(b)

Figure 3. Residuals Pattern: (a) without Run-outs; (b) with Run-outs.

Therefore, it can be concluded that Bootstrapping can be used for estimating parameter uncertainty only in the case of no run-outs.

\subsection{Bayesian Inference with Markov Chain Monte Carlo Implementation}

Bays' rule provides the mathematical basis to update beliefs (prior information) about a variable, $\theta$, given observations, $y$. By Bays' rule, the posterior probability of $\theta$ given observations, $p(\theta \mid y)$ is obtained as follows [35,36]:

$$
p(\theta \mid y)=\frac{p(\theta) p(y \mid \theta)}{p(y)},
$$

Future predictions for $y^{*}$ given observations $y$ is obtained from the predictive distribution

$$
p\left(y^{*} \mid y\right)=\int p\left(y^{*} \mid \theta\right) p(\theta \mid y) d \theta
$$

Thus, future predictions are modeled using the updated probability density function $p(\theta \mid y)$ similar to making a prediction for $y^{*}$ using a single value of $\theta$ in the classical statistical sense. Equation (8) can be estimated using Monte Carlo simulation strategies such as the Markov-Chain Monte-Carlo algorithm [36].

By definition, a Markov chain simulation is a sequence of random variables $\theta^{1}, \theta^{2}, \theta^{3}, \ldots$ for which for any $k$, the distribution of $\theta^{k}$ depends only on the most recent one $\theta^{k-1}$. In practice, several independent sequences of Markov chain simulations are created. The Metropolis algorithm is used to obtain the transition distribution function [31]. It is an adaption of a random walk that uses an acceptance/rejection rule to converge to the specified target distribution. The step-by-step procedure is as follows [27]: 
1. Select initial parameter vector

2. Iterate as follows for $k=1,2,3, \ldots$

a. Create a new trial position $\theta^{*}=\theta^{k-1}+\Delta \theta$, where $\Delta \theta$ is randomly sampled from the jumping distribution $q(\Delta \theta)$.

b. Create the Metropolis ratio.

$$
r=\frac{\pi\left(\left(\theta^{*} \mid y\right)\right)}{\pi\left(\left(\theta^{k-1} \mid y\right)\right)}
$$

3. Accept a new sample if:

$$
\theta^{k}=\left\{\begin{array}{lr}
\theta^{*} & \text { with probability } \min (r, 1) \\
\theta^{k-1} & \text { otherwise }
\end{array},\right.
$$

Note that this requires the jumping distribution to be symmetric: $q\left(\theta^{*}, \theta^{k-1}\right)=q\left(\theta^{k-1}, \theta^{*}\right)$. If the jumping distribution is not symmetric, then the Metropolis-Hasting algorithm [37] can be used where both sides jumping distributions are part of the ratio.

Since the posterior distribution can be calculated by Equation (7), where $p(y)$ is a normalizing constant, it also follows that the posterior density function can be written as:

$$
p(\theta \mid y) \propto p(\theta) p(y \mid \theta),
$$

i.e., the posterior distribution is proportional to the product of the prior and the likelihood functions.

If it is assumed that the prior distribution is the multivariate Normal distribution, then the Likelihood function becomes:

$$
p\left(y \mid \theta, \sigma^{2}\right)=\frac{1}{\sigma \sqrt{2 \pi}} \exp \left(-\frac{1}{2 \sigma^{2}} S S(\theta)\right)
$$

where,

$$
S S(\theta)=\sum_{i}^{n}(y-f(S, \theta))^{2},
$$

The Metropolis ratio becomes:

$$
r=\frac{p\left(\theta^{*} \mid y, \sigma^{2}\right)}{p\left(\theta^{k-1} \mid y, \sigma^{2}\right)}=\exp \left(-\frac{1}{2 \sigma^{2}}\left(S S\left(\theta^{*}\right)-S S\left(\theta^{k-1}\right)\right)\right),
$$

The scale reduction factor $R$ indicates a potential scale reduction for the considered distribution when the number of samples goes to infinity (see [38] for theory and more detailed descriptions). The sampling is said to converge if $R$ is close to one. Therefore, the number of simulations should be chosen such that $R$ becomes as close to one as possible, and thereby, the Monte Carlo sampling error close to zero.

The parameters fitted in the SN-curve in Equation (1) are $K$ and $m$. The correlation between them is illustrated in Figure 4. Here, the Markov Chain Monte Carlo algorithm is used. Furthermore, the Metropolis algorithm is applied for obtaining the transition distribution. Based on Reference [36], the scale reduction factor $R$ is also calculated to 1.0007 . 


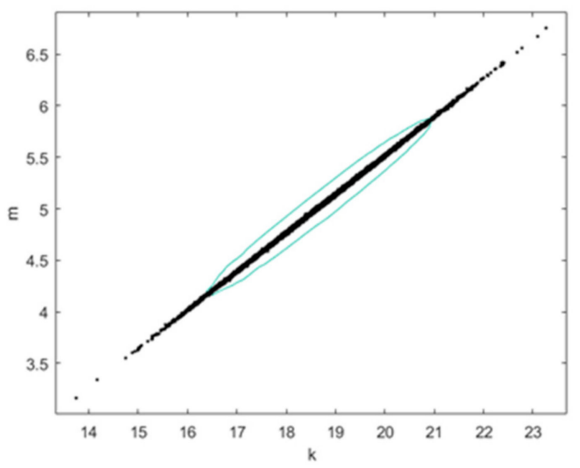

Figure 4. Correlation between $k$ and $m$

\section{Results of Uncertainty Modelling}

Table 2 shows a comparison between the results obtained by the methods presented above. This includes results obtained for the statistical parameters by MLM accounting for run-outs. Furthermore, a characteristic, $5 \%$ quantile is estimated using the MLM estimates resulting in $\log k=18.77$, which is larger than the characteristic value equal to 17.054 specified in the Eurocodes (see [38,39], and Table 2).

Table 2. Results.

\begin{tabular}{|c|c|c|c|c|c|c|}
\hline Parameter & $\begin{array}{l}\text { Mean by } \\
\text { MLM }\end{array}$ & $\begin{array}{l}\text { Mean by } \\
\text { Bayesian } \\
\text { Approach }\end{array}$ & $\begin{array}{c}\text { Standard } \\
\text { Deviation } \\
\text { by MLM }\end{array}$ & $\begin{array}{c}\text { Standard } \\
\text { Deviation } \\
\text { by Bayesian } \\
\text { Approach }\end{array}$ & Distribution & Remark \\
\hline$\varepsilon$ & 0 & 0 & - & - & Normal & Error term \\
\hline$\sigma_{\varepsilon}$ & 0.39 & 0.21 & 0.06 & 0.04 & Normal & $\begin{array}{c}\text { Standard deviation of error } \\
\text { term }\end{array}$ \\
\hline $\log k$ & 18.77 & 18.72 & 0.07 & 0.05 & Normal & $\begin{array}{l}\text { Location parameter in Wöhler } \\
\text { curve }\end{array}$ \\
\hline$m$ & Fixed to 5 & 5.03 & - & 0.02 & Fixed/Deterministic & $\begin{array}{l}\text { Slope of Wöhler curve } \\
\text { Correlation coefficient }\end{array}$ \\
\hline$\rho_{\log k, \sigma_{\varepsilon}}$ & & & 0.06 & 0.03 & Deterministic & $\begin{array}{l}\text { between location and standard } \\
\text { deviation of error }\end{array}$ \\
\hline
\end{tabular}

The Markov Chain Monte Carlo simulation results in Figure 5a show that log $k$ is mostly in the interval 18-19, and in Figure $5 b, m$ is close to 5, which is in agreement with the fixed value used for MLM. It should be noted that $m$ is assumed fixed in the reliability section. The Posterior marginal density function is also shown in Figure 6.

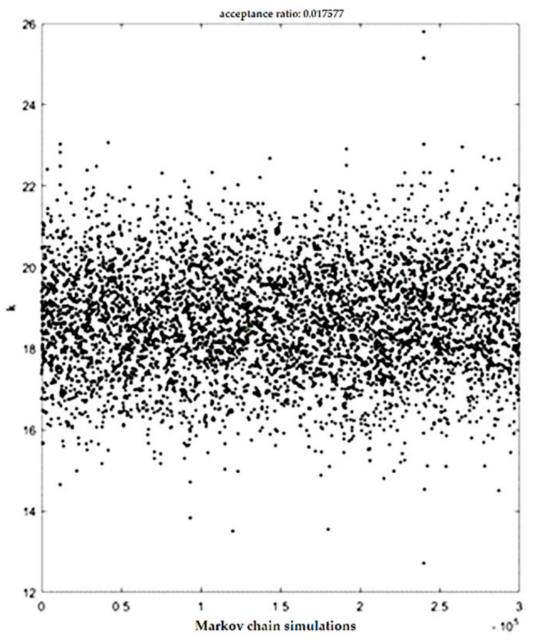

(a)

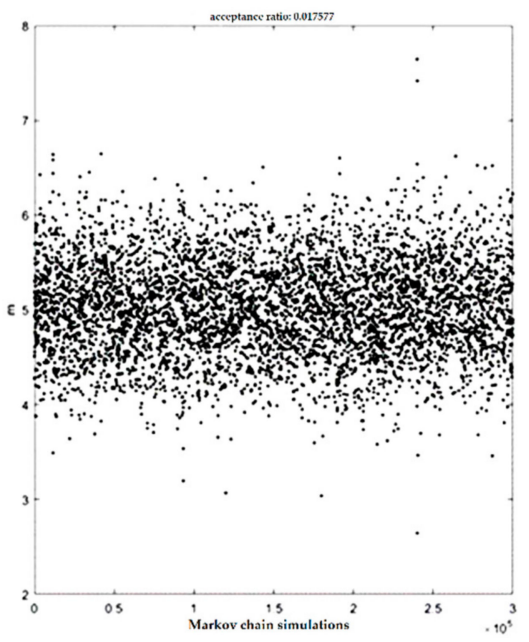

(b)

Figure 5. Markov Chain Simulation for: (a) $k$; (b) $m$. 

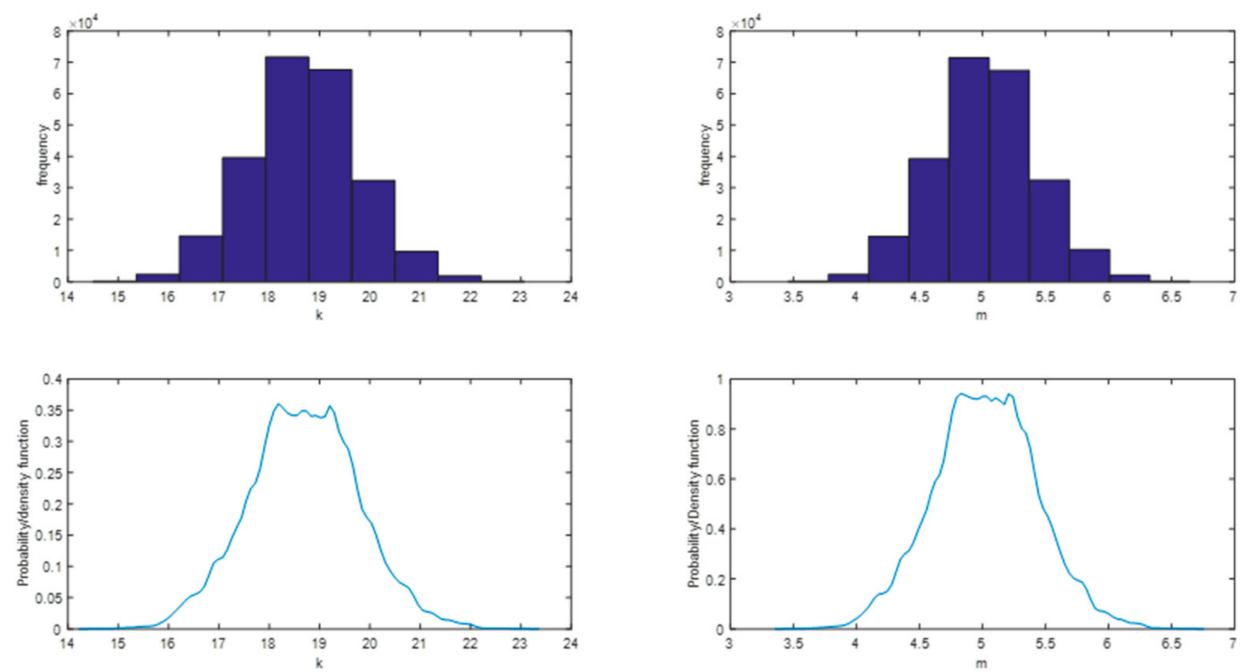

Figure 6. Posterior marginal density functions: (a) $k$; (b) $m$.

\section{Case Study: Crêt De l'Anneau Viaduct}

To illustrate the effect of change of model uncertainty of $\log k$, i.e., $\sigma_{\varepsilon}$ on the fatigue reliability of a structure, a case study of a composite (reinforced concrete deck and steel box girders) viaduct in Switzerland is chosen as seen in Figure 7.

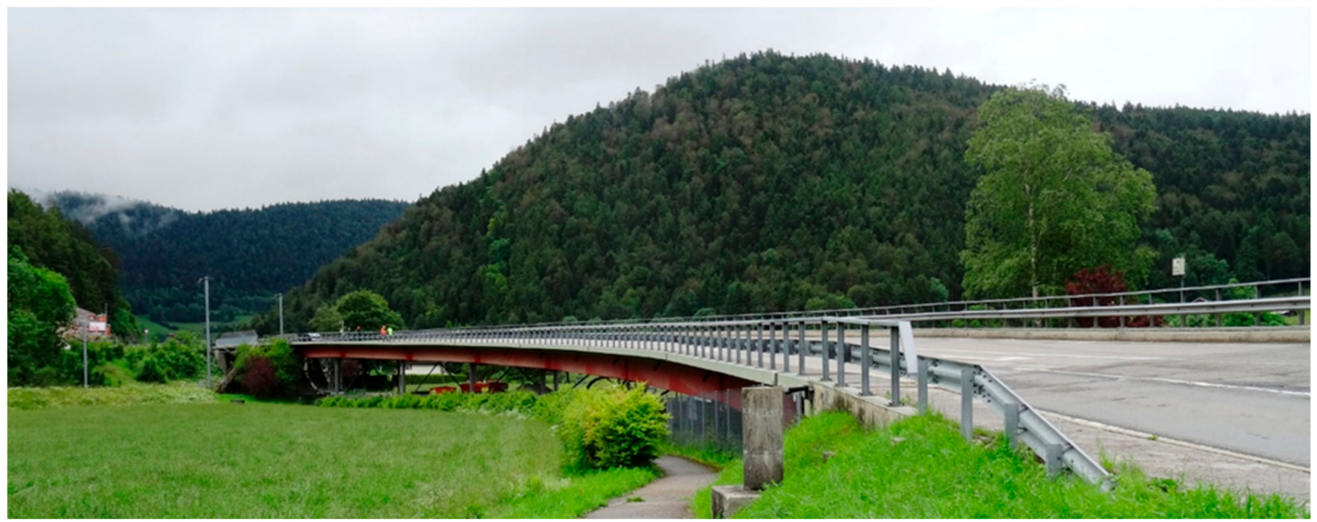

Figure 7. A view of Crêt De l'Anneau.

The identified fatigue critical location of this composite bridge is the reinforced concrete slab, as shown in [40] p.41. The fatigue behavior of the reinforced concrete deck slab is mainly governed by transverse bending between two girders. It contributes also to local longitudinal bending under vehicle rolling wheel loads, thus it is double bending behavior. The MCS department at EPFL has installed electrical strain gauges on reinforcement bars at critical location. This monitored strain data is used as action effects to perform fatigue reliability analysis of the viaduct, a reliability framework presented in [41] is used for the purpose.

\subsection{Limit State Equation}

A limit state equation for fatigue failure of critical reinforcement in the viaduct is formulated based on the Palmgren-Miner rule [42,43] assuming linear damage accumulation, Equation (15), and [41,44].

$$
g(t)=\Delta-\sum_{i=1}^{j} \frac{X_{n} n_{i} t}{10^{\varepsilon} \cdot k}\left(X_{W} R_{D} \Delta s_{i}\right)^{m}=0,
$$

where

$t$ indicates time $0<t<T_{L}$ in years, 
$T_{L}$ is the service life time of the structure,

$R_{D}$ is modelling the ratio of design parameters, here the section modulus of the deck slab, $\Delta s_{i}$ is the stress range for the $i$ th load bin.

All other terms in the limit state equation are explained in Table 3.

Table 3. Stochastic model for Wöhler curve.

\begin{tabular}{ccccc}
\hline Parameter & Distribution & Mean & Standard Deviation & Remark \\
\hline$\Delta$ & Lognormal & 1 & 0.30 & Model uncertainty related to PM Rule $^{1}$ \\
$X_{w}$ & Lognormal & 1 & 0.05 & Uncertainty in strain measurements \\
$X_{n}$ & Lognormal & 1 & 0.01 & Uncertainty in number of vehicles \\
$\log k$ & Normal & 18.77 & 0.07 & Location parameter in Wöhler curve \\
$m$ & Fixed & 5 & - & Slope of Wöhler curve fixed to $5^{2}$ \\
$\epsilon$ & Normal & 0 & $\sigma_{\varepsilon}$ & $\begin{array}{c}\text { Error term taken from Table } 2 \\
\text { Standard deviation of error term taken } \\
\text { from Table 2 }\end{array}$ \\
$\sigma_{\varepsilon}$ & Normal & $0.39 / 0.21^{3}$ & $0.06 / 0.004^{3}$ & $\begin{array}{c}\text { Correlation coefficient between location } \\
\text { and standard deviation of error taken } \\
\rho_{\log k, \sigma \varepsilon}\end{array}$ \\
& Deterministic & $0.06 / 0.003^{3}$ & - & from Table 2 \\
\hline
\end{tabular}

${ }^{1}$ model uncertainty obtained by fitting lognormal distribution to test data in [45]; ${ }^{2}$ slope of Wöhler curve fixed to 5 as $\log k$ and $\mathrm{m}$ are highly correlated with correlation coefficient equal to $0.9997 ;{ }^{3}$ two values are used for analysis first one from MLM approach, while the second one is from Bayesian approach.

\subsection{Reliability Analysis}

The First Order Reliability Method (FORM) is used for reliability analysis [2,46]. An open-source MATLAB-based toolbox, namely the FERUM (Finite Element Reliability Using MATLAB), is used for performing all FORM calculations [47]. The cumulative (accumulated) probability of failure in time interval $[0, t]$ is obtained by Equation (16):

$$
P_{F}(t)=P(g(t) \leq 0),
$$

The probability of failure is estimated by FORM [47]. The corresponding reliability index $\beta(t)$ is obtained by Equation (17):

$$
\beta(t)=-\phi^{-1}\left(P_{F}(t)\right),
$$

where, $\phi()$ is standardized normal distribution function.

The annual probability of failure is obtained by:

$$
\Delta P_{F}(t)=P_{F}(t)-P_{F}(t-\Delta t), t>1 \text { year },
$$

where $\Delta t=$ one year. The corresponding annual reliability index is denoted $\Delta \beta$.

\subsection{Reliability Results}

The cumulative reliability index along the service life of the structure is presented in Figure 8 for the case where uncertainty in vehicle number $X_{n}$ is $1 \%$ and $\operatorname{CoV}$ for $\log K$ is as 0.39 (MLM) and 0.2 (Bayesian).

Corresponding annual reliability index at 120 years is presented in Table 4.

Table 4. Annual reliability index as function of $\mathrm{CoV}$ of $\log k$

\begin{tabular}{cc}
\hline CoV of $\log k$ & Annual Reliability Index at 120 Years \\
\hline $0.39($ MLM) & 3.90 \\
0.20 (Bayesian) & 4.25 \\
\hline
\end{tabular}




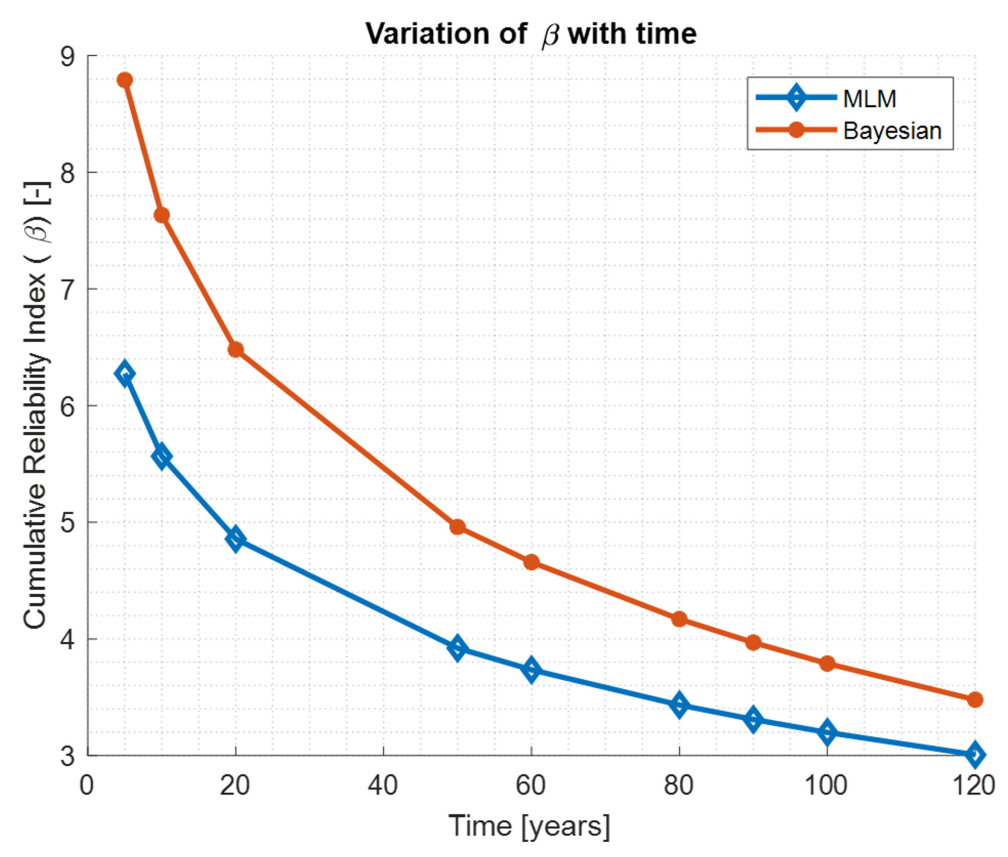

Figure 8. Reliability index as function of time.

The actual stress in slab of viaduct is very low, thus exhibiting a very high fatigue reliability. Current results are shown for the case of scaled stresses. Even after the scaling of the stresses annual reliability index is within acceptable levels, which is more than 3.7 (for the case of very high consequence and low efficiency of intervention, [48]). Furthermore, it can be seen from the results that CoV for $\log K$ has a very high influence on reliability index. Thus, estimating the $\mathrm{CoV}$ with great accuracy is very important in order to estimate the safety of the structures reasonably.

\section{Conclusions}

In this paper, for stochastic modeling of uncertainties for fatigue strength parameter, MLM as a common methodology is utilized to fit the statistical parameters in a regression model based on available test data. The Bootstrapping method is used to generate synthetic data. Example investigations in this paper indicate that Bootstrapping cannot be used if run-out data are to be accounted for. Thus, further steps are not proceeded to estimate statistical parameters. It should be mentioned that if the Bootstrapping method was fulfilled the requirement (random pattern), another methodology such as least square method or even Bootstrapping could be used for parameter estimation in the next step. Subsequently, the use of Bayesian inference with the Markov Chain Monto Carlo approach is studied.

Reliability analysis of a selected detail in the Cret De l'Anneau Viaduct is used to illustrate and compare different stochastic models obtained by the statistical methods. The results obtained by MLM is used in reliability analyses and is assumed as a prior for Bayesian. The results show difference in the reliability indices, indicating the importance of accurate estimation of the model uncertainty of the SN-curve. The results emphasize the choice of statistical method as it influences the reliability analyses. In this case study, Bayesian provided better statistical uncertainty, hence better fatigue reliability assessment.

Author Contributions: The main idea for the paper was proposed by S.R. S.R. wrote the first draft of the paper, except Section 4 which was drafted by A.M. S.R., A.M. and S.B. provided literature review. S.R. developed the methodology wrote relevant codes for Maximum likelihood method, Markov Chain Monte Carlo, Bayesian inference and Bootstrap and reviewed by A.M. A.M. developed the reliability framework with relevant codes with input for stochastic model from S.R. S.R. and A.M. post-processed the results. J.D.S. supervised the findings of this work and reviewed methodology. S.R., A.M., J.D.S. and S.B. contributed for articulate the research work in its current form as full research manuscript. All authors discussed the results and contributed to the final results. All authors have read and agreed to the published version of the manuscript. 
Funding: Current work is carried out under the project INFRASTAR (infrastar.eu), which has received funding from the European Union's Horizon 2020 research and innovation program under the Marie Skłodowska-Curie grant agreement No. 676139. The grant is gratefully acknowledged.

Acknowledgments: These current codes were further developed based on codes provided in DTU Summer School on Uncertainty and sensitivity analysis of numerical models-7-11 August 2017, lecturer: Gurkan Sin, to suit current application.

Conflicts of Interest: The authors declare no conflict of interest.

\section{References}

1. Hansen, L.P.; Heshe, G. Static, Fire and Fatigue Tests of Ultra High-Strength Fibre Reinforced Concrete and Ribbed Bars. J. Nord. Concr. Res. 2001, 26, 17-37.

2. Sørensen, J. Notes in Structural Reliability Theory and Risk Analysis; Aalborg University: Aalborg, Denmark, 2011.

3. Madsen, H.O.; Krenk, S.; Lind, N.C. Methods of Structural Safety; Prentice-Hall: Upper Saddle River, NJ, USA, 1986.

4. Ditlevsen, O.; Madsen, H. Structural Reliability Methods; Wiley: Hoboken, NJ, USA, 1996.

5. Faber, M.H. Risk Assessment in Engineering (Principles, System Representation \& Risk Criteria). Available online: https://www.jcss.byg.dtu.dk/-/media/Subsites/jcss/english/publications/risk_assessment_in_ engineering/jcss_riskassessment.ashx?la=da\&hash=F4BD53E6E9C2AD6242FD54762719D55BD251A995 (accessed on 15 November 2019).

6. Kaplan, S.; Garrick, B.J. On the Quantitative Definition of Risk. Risk Anal. 1981, 1, 11-27. [CrossRef]

7. Modarres, M. Risk Analysis in Engineering: Techniques, Tools, and Trends; CRC Press: Boca Raton, FL, USA, 2006.

8. Zio, E.; Baraldi, P.; Cadini, F. Basics of Reliability and Risk Analysis: Worked Out Problems and Solutions; World Scientific Publishing Co. Pte. Ltd.: Singapore, 2011.

9. Zio, E. Introduction To The Basics Of Reliability And Risk Analysis [Elektronisk resurs]; World Scientific Publishing Co. Pte. Ltd.: Singapore, 2007.

10. Chemweno, P.; Pintelon, L.; Muchiri, P.N.; Van Horenbeek, A. Risk assessment methodologies in maintenance decision making: A review of dependability modelling approaches. Reliab. Eng. Syst. Saf. 2018, 173, 64-77. [CrossRef]

11. Aven, T.; Zio, E. Knowledge in Risk Assessment and Management; John Wiley \& Sons: Hoboken, NJ, USA, 2018.

12. Pham, H. Bayesian Inference for Probabilistic Risk Assessment; Springer: Berlin, Germany, 2005.

13. Fenton, N.; Neil, M. Risk Assessment and Decision Anlysis with Bayesian Networks; CRC Press: Boca Raton, FL, USA, 2013.

14. Singpurwla, N.D. Reliability and Risk. A Bayesian Perspective; John Wiley \& Sons, Ltd.: Chichester, UK, 2006.

15. Aven, T. Risk assessment and risk management: Review of recent advances on their foundation. Eur. J. Oper. Res. 2016, 253, 1-13. [CrossRef]

16. Lair, J.; Rissanen, T.; Sarja, A. Methods for Optimisation and Decision Making in Lifetime Management of Structures. 2004. Available online: https://www.scribd.com/document/342349363/METHODS-FOROPTIMISATION-AND-DECISION-MAKING-IN-LIFETIME-MANAGEMENT-OF-STRUCTURES (accessed on 15 November 2019).

17. Vrouwenvelder, A.; Holicky, B.M.; Tanner, C.P.; Lovegrove, D.R.; Canisius, E.G. Risk Assessment and Risk Communication in Civil Engineering. 2001. Available online: https://www.irbnet.de/daten/iconda/CIB14314. pdf (accessed on 15 November 2019).

18. Bhattacharya, B. Risk and Reliability in Bridges. Innovative Bridge Design Handbook; Elsevier: Amsterdam, The Netherlands, 2016.

19. Bahrebar, S.; Zhou, D.; Rastayesh, S.; Wang, H.; Blaabjerg, F. Reliability assessment of power conditioner considering maintenance in a PEM fuel cell system. Microelectron. Reliab. J. 2018, 88-90, 1177-1182. [CrossRef]

20. Rastayesh, S.; Bahrebar, S.; Bahman, A.S.; Dalsgaard Sørensen, J.; Blaabjerg, F. Lifetime Estimation and Failure Risk Analysis in a Power Stage Used in Wind-Fuel Cell Hybrid Energy Systems. Electronics 2019, 8, 1412. [CrossRef]

21. Rastayesh, S.; Long, L.; Dalsgaard Sørensen, J.; Thöns, S. Risk Assessment and Value of Action Analysis for Icing Conditions of Wind Turbines Close to Highways. Energies 2019, 12, 2653. [CrossRef] 
22. Màrquez-Dominguez, S. Reliability-Based Design and Planning of Inspection and Monitoring of OffshoreWind Turbines; Aalborg University: Aalborg, Denmark, 2013.

23. Mankar, A.; Rastayesh, S.; Dalsgaard Sørensen, J. Sensitivity and Identifiability Study for Uncertainty Analysis of Material Model for Concrete Fatigue. In Proceedings of the 5th International Reliability and Safety Engineering Conference, Shiraz University, Shiraz, Iran, 9-10 May 2018.

24. Seber, G.; Wild, C. Non-Linear Regression; Wiley: Hoboken, NJ, USA, 1989.

25. Rastayesh, S.; Bahrebar, S.; Blaabjerg, F.; Zhou, D.; Wang, H.; Dalsgaard Sørensen, J. A System Engineering Approach Using FMEA and Bayesian Network for Risk Analysis-A Case Study. Sustainability 2020, 12, 77. [CrossRef]

26. Rastayesh, S.; Sønderkær Nielsen, J.; Dalsgaard Sørensen, J. Bayesian Network Methods for Risk-Based Decision Making for Wind Turbines. In Proceedings of the EAWE PhD Seminar on Wind Energy, Brussel, Belgium, 18-20 September 2018.

27. Metropolis, N.; Ulam, S. The Monte Carlo method. J. Am. Stat. Assoc. 1949, 44, 335-341. [CrossRef] [PubMed]

28. MC1990, FIB Model Code for Concrete Structures 1990; Ernst \& Sohn: Berlin, Germany, 1993.

29. MC2010, FIB Model Code for Concrete Structures 2010; Ernst \& Sohn: Berlin, Germany, 2013.

30. Høvik, S. DNV OS C 502, DNV OS C 502, Offshore Concrete Structures; DNVGL: Høvik, Norway, 2012.

31. Rastayesh, S.; Mankar, A.; Sørensen, J.D. Comparative investigation of uncertainty analysis with different methodologies on fatigue data of rebars. In Proceedings of the 5th International Reliability and Safety Engineering Conference, Shiraz, Iran, 9-10 May 2018.

32. Lindley, D. Introduction to Probability and Statistics from a Bayesian Viewopoint, vol. 1+2; Cambridge University Press: Cambridge, UK, 1976.

33. Efron, B. Bootstrap Methods: Another Look at the Jackknife. Ann. Stat. 1979, 7, 1-26. [CrossRef]

34. Sin, G.; Gernaey, K.V. Data Handling and Parameter Estimation. In Experimental Methods in Wastewater Treatment; IWA Publishing: London, UK, 2016; Volume 281780404745.

35. Alfredo, H.; Tang, W.H. Probability Concepts in Engineering: Emphasis on Applications in Civil E Environmental Engineering, 2nd ed.; Wiley: Hoboken, NJ, USA, 2007.

36. Gelman, A.; Carlin, J.B.; Stern, H.S.; Dunson, D.B.; Vehtari, A.; Rubin, D. Bayesian Data Analysis; A Champman \& Hall Book: New York, NY, USA, 2003.

37. EN 1990, Eurocode 0: Basis for Structural Design; Cen: Brussels, Belgium, 2002.

38. Hastings, W.K. Monte Carlo sampling methods using Markov chains and their applications. Biometrika 1970, 57, 97-109. [CrossRef]

39. EN 1992-1-1, Eurocode 2: Design of Concrete Structures - Part 1-1: General Rules and Rules for Buildings; Cen: Brussels, Belgium, 2004.

40. MCS. Surveillance du Viaduc du Crêt de l'Anneau par un Monitoring à Longue Durée; MSC: Lausanne, Switzerland, 2017.

41. Mankar, A.; Rastayesh, S.; Dalsgaard Sørensen, J. Fatigue reliability analysis of Crêt de l'Anneau viaduct: A case study. Struct. Infrastruct. Eng. 2019. [CrossRef]

42. Palmgren, A. Die lebensdauer von kugellagern (The life of ball bearings). Zeitschrift Des Vereins Deutscher Ingenieure 1924, 68, 339-341.

43. Miner, M.A. Cumulative damage in fatigue. Am. Soc. Mech. Eng. J. Appl. Mech. 1945, 12, 159-164.

44. Mankar, A.; Rastayesh, S.; Dalsgaard Sørensen, J. Fatigue Reliability analysis of Cret De l'Anneau Viaduct: A case study. In Proceedings of the IALCCE 2018, Ghent, Belgium, 18-31 October 2018.

45. CEB 1988. Fatigue of Concrete Structures - State of Art Report; CEB: Zurich, Switzerland, 1989.

46. Madsen, H.O.; Krenk, S.; Lind, N.C. Methods of Structural Safety; Dover Publications: New York, NY, USA, 2006.

47. FERUM. Finite Element Reliability Using Matlab; University of California Berkeley: Berkeley, CA, USA, 2010.

48. SIA-269, Existing Structures-Bases for Examination and Interventions; Swiss Society of Engineers and Architects: Zurich, Switzerland, 2016.

(C) 2020 by the authors. Licensee MDPI, Basel, Switzerland. This article is an open access article distributed under the terms and conditions of the Creative Commons Attribution (CC BY) license (http://creativecommons.org/licenses/by/4.0/). 